\title{
CABECEIRAS DE DRENAGEM E CONTROLE ESTRUTURAL NA BACIA HIDROGRÁFICA DO ARROIO LAJEADO TAQUAREMBÓ-RS
}

\author{
Vinícius Duarte Guareschi ${ }^{(a)}$, Andréa Valli Nummer ${ }^{(b)}$ \\ (a) Departamento de Geociências, Universidade Federal de Santa Maria, vdguareschi @ yahoo.com.br \\ (b) Departamento, Geociências, Universidade Federal de Santa Maria, a.nummer@ gmail.com
}

\section{EIXO: SISTEMAS GEOMORFOLÓGICOS: ESTRUTURA, DINÂMICAS E PROCESSOS}

\begin{abstract}
Resumo
Este trabalho tem como objetivo identificar e mapear as depressões fechadas e as cabeceiras de drenagem na bacia hidrográfica do Arroio Lajeado Taquarembó, no Planalto Meridional do Rio Grande do Sul, bem como verificar a influência do controle estrutural para a gênese destas feições. Verificou-se que as fraturas condicionam a geometria e a orientação das cabeceiras de drenagem. As cabeceiras exibem orientações predominantemente NE e SE, coincidentes com os principais grupos de lineamentos morfoestruturais que ocorrem na bacia.
\end{abstract}

Palavras chave: Depressões fechadas; Cabeceiras de drenagem, Controle estrutural, Planalto Meridional do RS.

\section{Introdução}

No Planalto Meridional do Rio Grande do Sul, é considerável o número de cabeceiras de drenagens com diferentes propriedades morfológicas. Algumas concavidades são rasas, com formato arredondado, ou alongado, outras apresentam diversas ramificações e se estendem por centenas de metros, enquanto outras são mais amplas e entalhadas. Também é comum a ocorrência de depressões fechadas a uma distância crítica dos divisores apresentando certo alinhamento com as cabeceiras de drenagem.

Maciel Filho, Cabral e Spinelli (1993), Gontan e Maciel Filho (1998), Gontan (2002) e Maciel Filho et al. (2013) atribuem a origem destas feições no Planalto Meridional do Rio Grande do Sul a fatores tectônicos como falhas e fraturas e ao intemperismo químico de materiais menos resistentes.

Alguns autores como Felizola; Boulet (1994), Castro; Coelho Netto (2002) e Coelho Netto (2003) relacionam a ocorrência de depressões fechadas com a abertura de vales de cabeceira sob forte controle estrutural. Os autores atribuem fundamental importância para os processos de denudação química na formação das depressões, argumentando que somente processos de natureza física como a remoção superficial de material não poderiam originar tais feições.

No alto vale do rio Sargento, Oeste de Santa Catarina, em rochas vulcânicas básicas a intermediárias, Bragas et al. (2006), destaca que o grande número de concavidades registradas no mapeamento chama a 
atenção por se concentrarem no setor de topo da bacia hidrográfica e também por estarem distribuídas ao longo dos canais de $1^{\mathrm{a}}$ ordem.

Na bacia hidrográfica do Rio Quatorze, na Formação Serra Geral - SW/Paraná, Paisani; Pontelli; Geremia (2006), ao analisarem a distribuição espacial das cabeceiras de drenagem concluem que estas feições em sua maioria ocorrem em superfície aplainada do topo do Planalto. Ao caracterizarem a forma dessas feições, definidas pelo índice de circularidade, constataram que são feições circulares e rasas e que a maioria das cabeceiras são controladas por fraturas.

Neste sentido, o objetivo deste trabalho é realizar a identificação e mapeamento das depressões fechadas na bacia hidrográfica do Arroio Lajeado Taquarembó, bem como verificar a relação destas feições com os lineamentos morfoestruturais que ocorrem na área.

\section{2. Área de Estudo}

A bacia hidrográfica do Arroio Lajeado Taquarembó possui área de 28,62 $\mathrm{Km}^{2}$ e está localizada no Planalto Meridional do Rio Grande do Sul drenando parte da margem esquerda da bacia hidrográfica do Rio Guassupi (Figura 1). O Planalto Meridional pode ser compartimentalizado em duas unidades de relevo: Rebordo do Planalto ou Serra Geral e Topo do Planalto ou Planalto dos Campos Gerais (MACIEL FILHO; CABRAL; ESPINELLI, 1994).

A Unidade Geomorfológica Planalto dos Campos Gerais onde está inserida a área de estudo apresenta superfície inclinada com caimento natural para oeste, caracterizando-se por um relevo plano e conservado, representado por superfícies de aplanamento (JUSTUS, MACHADO; FRANCO, 1986) formado por rochas vulcânicas de idade Mesozóica, pertencentes à Formação Serra Geral.

As rochas vulcânicas do topo do Planalto pertencem a Fácies Caxias, caracterizada por derrames de composição intermediária a ácida, de riodacitos a riolitos, com forte disjunção tabular no topo dos derrames e maciço na porção central, dobras de fluxos e autobrechas freqüentes, vesículas preenchidas dominantemente por calcedônias e ágata, fonte de mineralização da região (Wildner, 2008). 


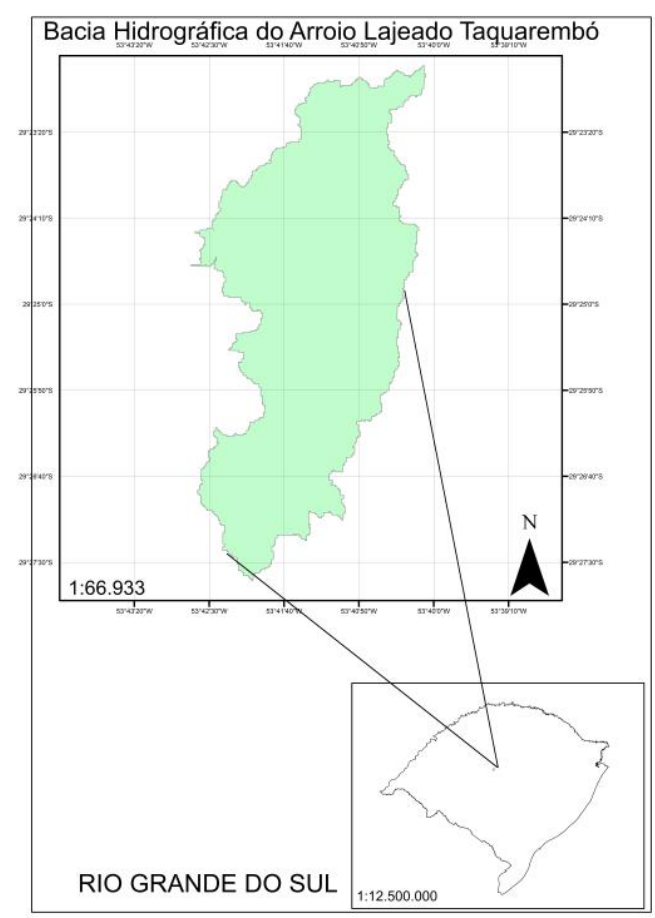

Figura 1 - Localização da Bacia Hidrográfica do Arroio Lajeado Taquarembó.

\section{Metodologia}

O mapeamento das depressões fechadas e das cabeceiras de drenagem foi realizado com base em imagens orbitais Ikonos disponíveis no software Google Earth Pro. A vetorização das feições foi realizada diretamente sobre a imagem de satélite no monitor do computador.

Os lineamentos morfoestruturais (falhas e fraturas) foram vetorizados diretamente no monitor sobre a imagem do Google Earth Pro, em escala detalhada, a fim deixar o procedimento de extração mais completo. Posteriormente, o arquivo digital foi importado para o ArcGis $10 \mathrm{e}$ integrado ao banco da dados. Ao final do processo de extração obteve-se um total de 378 lineamentos.

Para determinar o índice de circularidade das cabeceiras de drenagem, adotou-se a metodologia utilizada por Paisani, Pontelli e Geremia (2006). Quanto mais próximo de 1,0 for o índice de circularidade, mais próxima de um círculo perfeito será a feição, sugerindo que a cabeceira encontra-se em um estágio de evolução inicial. A equação utilizada para definir o índice de circularidade é a seguinte:

$\mathrm{IC}=\mathrm{A} \backslash \mathrm{Ac}$, onde IC = índice de circularidade; $\mathrm{A}=$ área da cabeceira de drenagem; $\mathrm{Ac}=$ área de um círculo com mesmo perímetro da cabeceira de drenagem. 
Em virtude do grande número de cabeceiras, o índice de circularidade foi calculado automaticamente no software ArcGis. As depressões fechadas não tiveram seu índice de circularidade determinado devido ao pequeno tamanho que apresentam o que poderia incorrer em certa imprecisão.

Para relacionar o controle estrutural na origem das cabeceiras de drenagem, realizou-se a comparação entre os grupos de lineamentos e a orientação dos eixos das cabeceiras.

\section{Distribuição espacial das cabeceiras de drenagem e das depressões fechadas}

No Planalto Meridional do Rio Grande do Sul sobre a formação Serra Geral, onde está inserida a bacia do Arroio Lajeado Taquarembó é comum na paisagem à ocorrência de depressões fechadas próximas aos divisores em alguns casos com acúmulo de água formando pequenas lagoas. Destaca-se também a ocorrência de depressões quase fechadas com formas circulares ou alongadas contendo o fundo coberto por solos hidromórficos com uma das extremidades rebaixadas para escoamento das águas, constituindo-se nas cabeceiras de drenagem.

A bacia hidrográfica do Arroio Lajedo Taquarembó apresenta uma amplitude altimétrica de 92 metros, tendo como maior cota 523 metros e a menor 431metros, localizando-se no topo plano do Planalto Meridional (Figura 2). 


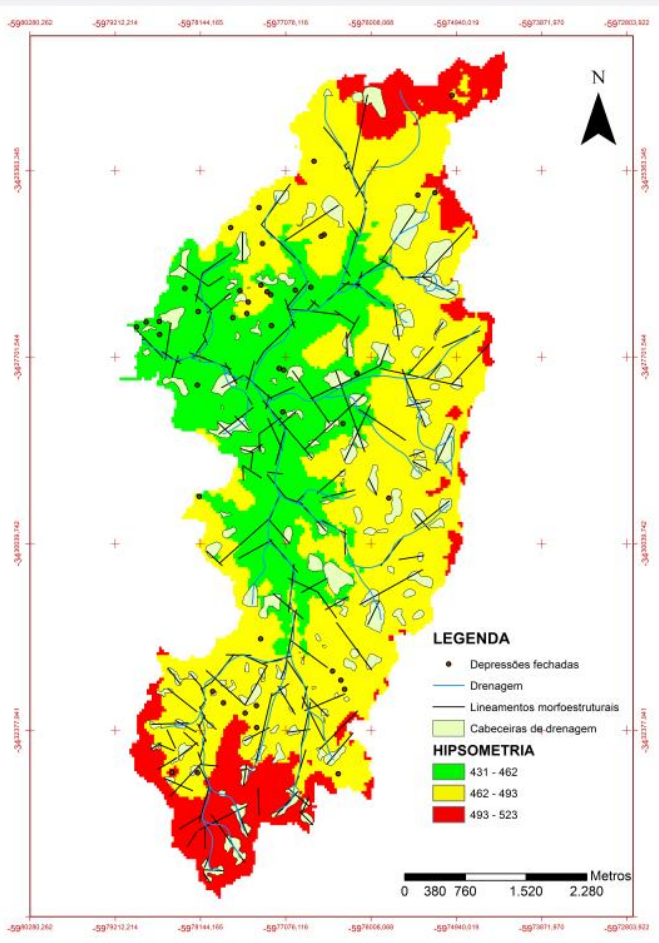

Figura 2 - Mapa hipsométrico contendo as cabeceiras de drenagens, depressões fechadas e os lineamentos morfoestruturais da área de estudo.

Foram identificadas e mapeadas 139 cabeceiras de drenagem e 42 depressões fechadas na bacia hidrográfica. Guareschi e Nummer (2012) constataram que 63\% das depressões fechadas e cabeceiras de drenagem na bacia e adjacências, situam-se acima de 440 metros, coincidindo com o domínio das rochas ácidas da Fácies Caxias (WILDNER, 2008). A Figura 3 ilustra uma depressão fechada e uma cabeceira de drenagem.

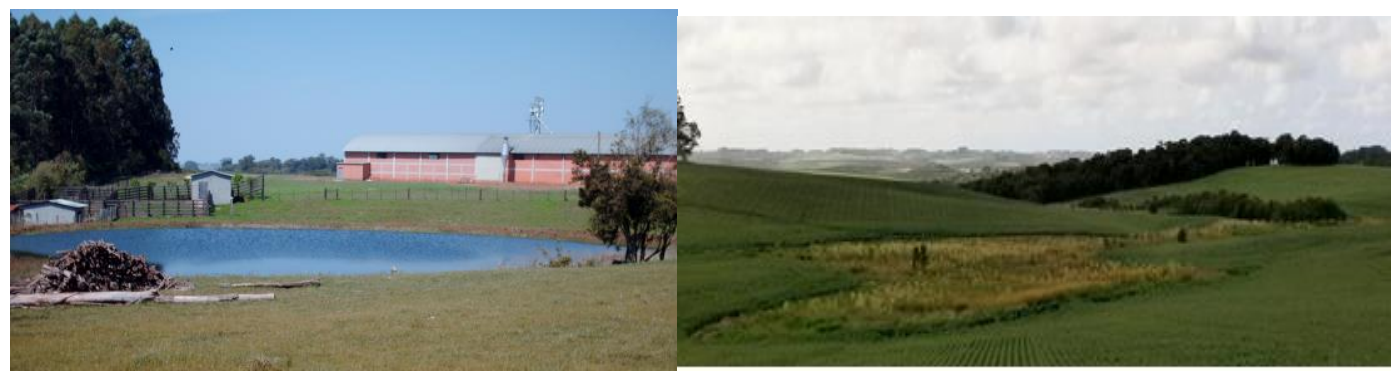

Figura 3 - Depressão fechada e cabeceira de drenagem, respetivamente. 


\section{Controle estrutural e a relação com as cabeceiras e as depressões fechadas}

A partir de imagens orbitais Ikonos disponíveis no software Google Earth Pro foram identificados e mapeados 378 lineamentos morfoestruturais (falhas e fraturas). Destacam-se duas direções predominantes de fraturas na área de estudo, representadas pelos grupos NE e SE (Tabela I).

Tabela I - Direção, população e comprimento médio dos principais grupos de lineamentos que ocorrem na área de estudo.

\begin{tabular}{c|c|c|c}
\hline Classe & Direção & População & Comprimento médio (m) \\
\hline $\mathrm{NE}$ & $25,3^{\circ}-65,5^{\circ}$ & 106 & 199,9 \\
\hline $\mathrm{SE}$ & $120,1^{\mathrm{o}}-159,5^{\circ}$ & 125 & 156,9 \\
\hline
\end{tabular}

O grupo SE apresenta o maior número de lineamentos e suas estruturas condicionam os cursos d'água de primeira ordem da bacia. Já o grupo NE possuí as estruturas mais longas e associadas aos tributários do Arroio Lajeado Taquarembó.

Para verificar a associação do controle estrutural com as cabeceiras foram contabilizadas o número destas feições que exibem orientação de seus eixos na mesma direção dos principais grupos de lineamentos da bacia. De 139 cabeceiras, 76,2\% estão alinhadas com os grupos de fraturas predominantes na área de estudo (NE e SE) conforme mostra a tabela II.

Tabela II - Direção dos lineamentos e das cabeceiras de drenagem na área de estudo.

\begin{tabular}{c|c|c|c}
\hline Feições & Direções & $\mathbf{n}^{\circ}$ de casos & percentual \\
\hline \multirow{2}{*}{ Lineamentos } & $25,3^{\circ}-65,5^{\circ}$ & 106 & 28 \\
\cline { 2 - 4 } & $120,1^{\circ}-159,5^{\circ}$ & 125 & 33 \\
\hline \multirow{3}{*}{ Cabeceiras de drenagem } & $25,3^{\circ}-65,5^{\circ}$ & 50 & 35,9 \\
\cline { 2 - 4 } & $120,1^{\circ}-159,5^{\circ}$ & 56 & 40,3 \\
\hline
\end{tabular}

O restante das cabeceiras que são controladas por fraturas exibem orientações que coincidem com os demais grupos de lineamentos.

O diagrama de rosetas mostra a distribuição das cabeceiras de drenagem e dos lineamentos morfoestruturais na área de estudo. 


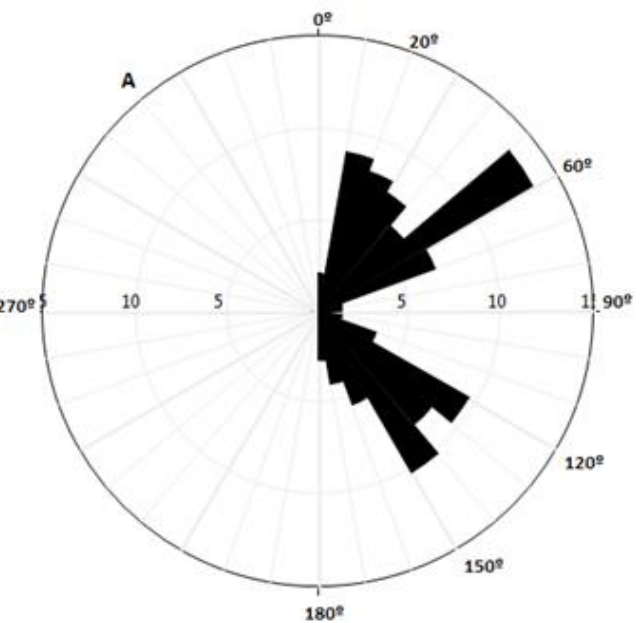

28 de Junho à 02 de Julho de 2017

Figura 4: Orientação das cabeceiras de drenagem (A) e orientação dos lineamentos (B).

De acordo com os diagramas é possível observar que entre os grupos NE e SE, os lineamentos que mais estão relacionados a gênese das cabeceiras são os de direção NE $50^{\circ}$ e SE $120^{\circ}$ e $150^{\circ}$.

\section{Morfometria das cabeceiras de drenagem}

Para a obtenção do índice de circularidade das cabeceiras de drenagem mediu-se a área e o perímetro das cabeceira. A área das cabeceiras varia entre 0,00011 a $0,15 \mathrm{~km}^{2}$ com média $0,020 \mathrm{~km}^{2}$, enquanto que o perímetro situa-se entre 0,04 e $1,75 \mathrm{Km}^{2}$ com média de $0,57 \mathrm{~km}^{2}$. O índice de circularidade varia de 0,2 até 0,99 , sendo distribuídas em oito classes. Considerou-se que o intervalo de classes 0,61-0,70 e 0,9-0,99 como representativo de cabeceiras mais circulares.

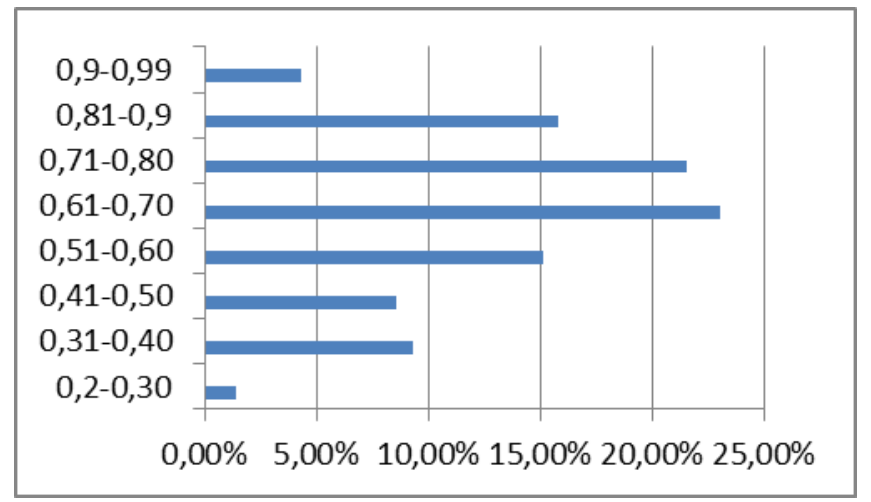

Figura 5-Frequência dos valores do índice de circularidade por classe.

A maioria das cabeceiras da bacia apresenta forma circular, com $65 \%$ das feições situadas no intervalo de classe mencionado acima, indicando que seu desenvolvimento ainda encontra-se em estágios iniciais. 


\section{Conclusões}

As cabeceiras de drenagens e as depressões fechadas distribuem-se no topo do Planalto Meridional sob rochas ácidas da formação Serra Geral. As depressões fechadas estão localizadas preferencialmente nos divisores ocupando as porções mais planas do terreno, enquanto que as cabeceiras distribuem-se por toda a bacia em diferentes faixas altimétricas. A drenagem é controlada pelo principal sistema de trends da área (NE-SO e NO-SE). Estas fraturas originam um padrão de drenagem paralelo e controlam os cursos d'água da bacia.

É considerável o número de depressões fechadas que apresentam alinhamento entre si e com as cabeceiras de drenagens da bacia. Verificou-se que as fraturas condicionam a geometria e a orientação das cabeceiras de drenagem. As cabeceiras que exibem orientações coincidentes com as principais famílias de lineamentos morfoestruturais que ocorrem na bacia, ou seja, NE $\left(25,3^{\circ}-65,5^{\circ}\right)$ e SE $\left(120,1^{\circ}-159,5^{\circ}\right)$ representam um total de $76,2 \%$.

O índice de circularidade das cabeceiras indica o grau de evolução morfológica destas feições e revela a intensidade de atuação dos processos morfogênicos. As cabeceiras de drenagem da bacia tentem a forma circular, fato que evidencia o baixo padrão evolutivo destas feições provavelmente imposto pela resistência da rocha vulcânica de constituição levemente ácida frente aos processos de intemperismo.

\section{Bibliografia}

AVELAR, A. S.; COELHO NETTO, A. L. Fraturas e desenvolvimento de unidades geomorfológicas côncavas no médio vale do Rio Paraíba do Sul. Revista Brasileira de Geociências, v.22, n.2, p.222-227, 1992.

COELHO NETTO, A. L. Evolução de cabeceiras de drenagem no médio vale do Rio Paraíba do Sul (SP/RJ): a formação e o crescimento da rede de canais sob controle estrutural. Revista Brasileira de Geomorfologia, n. 2, p. 69-100, 2003.

FELIZOLA, H. F.; BOULET, B. Evolution and opening of closed depressions devoloped in a quartz-kaolinitic sedimentary substratum at Taubaté basin (São Paulo, Brazil), and analogy to the slope evolution. Geomorphology, v.16 p.77-86, 1994.

GONTAN. J. E. N. Mapeamento e caracterização de feições pseudo-cársticas em duas áreas do Rio Grande do Sul, através de técnicas e sensoriamento remoto e SIG. 2002. 81f. Dissertação (Mestrado em Engenharia Agrícola) - Universidade Federal de Santa Maria, Santa Maria, 2002.

GONTAN, J. E. N., MACIEL FILHO, C. L. Levantamento das feições cársticas no planalto vulcânico do Rio Grande do Sul - Área de São Martinho da Serra. In: Congreso Uruguayo De Geologia, 2., 1998, Punta Del Leste. Anais... Punta Del Leste: SUG, 1998. p. 442-446.

MACIEL FILHO, C. L.; CABRAL, I. L. L.; SPINELLI, J. Feições Semelhantes à Morfologia Cárstica no Planalto Vulcânico do Rio Grande do Sul. In: SIMPÓSIO DE GEOGRAFIA FÍSICA APLICADA, 5., 1993b, São Paulo. Anais... São Paulo: Universidade de São Paulo, 1994, p. 147-150. 


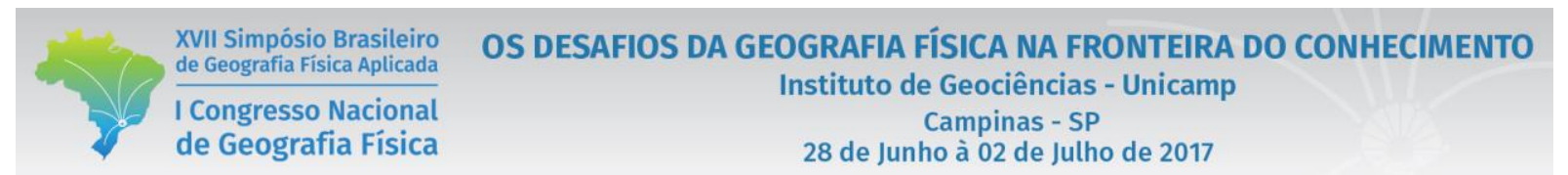

MACIEL FILHO, C. L. et al. Feições de carste sobre a formação Serra Geral na região de Vacaria, RS, e Lages, SC.

Revista Caminhos de Geografia. Uberlândia v. 14, n. 48 p. 197-208, 2013.

PAISANI, J. C., PONTELLI, M. E., GEREMIA, F. Cabeceiras de drenagem da Bacia do Rio Quatorze - Formação Serra Geral (SW do Paraná): Distribuição espacial, propriedades morfológicas e controle estrutural. RA'eGA, Curitiba, n. 12, p. 211-219, 2006. 